\title{
The association between metabolic syndrome and elevated serum alanine transaminase levels in an indigenous population in Northern Taiwan: a community-based study
}

\author{
Yi-Fang Chen \\ Chang Gung Memorial Hospital \\ Yen-An Lin \\ Chang Gung Memorial Hospital \\ Wei-Chung Yeh \\ Chang Gung Memorial Hospital \\ Yu-Chung Tsao \\ Chang Gung Memorial Hospital \\ Wen-Cheng Li \\ Chang Gung Memorial Hospital \\ I-Ju Chen \\ Chang Gung Memorial Hospital \\ Jau-Yuan Chen ( $\nabla$ welins@cgmh.org.tw ) \\ Chang Gung Memorial Hospital https://orcid.org/0000-0001-9195-7833
}

Research article

Keywords: Metabolic Syndrome, Alanine Transaminase, Indigenous populations, Northern Taiwan, Risk Factors

Posted Date: May 25th, 2020

DOI: https://doi.org/10.21203/rs.3.rs-15642/v2

License: (c) (1) This work is licensed under a Creative Commons Attribution 4.0 International License. Read Full License 


\section{Abstract}

Background: Metabolic syndrome (MetS), a prevalent health condition in Taiwan, places individuals at higher risk of cardiovascular disease, diabetes, and stroke. Therefore, the identification of risk factors associated with MetS is crucial. Nevertheless, only limited studies about MetS have been conducted among indigenous peoples in Taiwan; these studies identified a high prevalence of MetS among an indigenous population, which encouraged us to investigate further. Thus, our study aims to determine the prevalence of MetS among the northern Taiwanese indigenous population and to explore the relationship between MetS and associated risk factors, especially serum alanine transaminase (ALT).

Methods: This is an observational, population-based, cross-sectional study that was conducted in remote villages of an indigenous community in northern Taiwan between 2010 and 2015. A total of 454 participants, $47.36 \%$ male and $52.64 \%$ female, were eligible for analysis. The participants underwent anthropometric assessment and measurements of blood pressure, serum triglyceride levels, fasting plasma glucose levels, serum HDL-C levels and serum ALT levels. MetS was defined based on the revised NCEP/ATPIII criteria from Taiwan Health Promotion Administration.

Results: A total of 454 participants were included in the analysis. There were 277 people with MetS and 177 people without. The prevalence of MetS was $61.01 \%$. The average age was 49.50 years old. People with MetS had a significantly higher ALT level (24.00 (17-36) U/L vs. 19.00 (15-26) U/L, $p<0.001)$ than those without MetS. In addition, the chi-square comparison showed that participants with ALT levels>36 $\mathrm{U} / \mathrm{L}$ had a tendency towards a higher prevalence of MetS $(76.7 \%$ vs. $57.3 \%, p=0.001)$ than those with ALT levels $\leq 36 \mathrm{U} / \mathrm{L}$. The adjusted odds ratio (OR) of ALT levels $>36 \mathrm{U} / \mathrm{L}$ for MetS was 2.79 (95\% Cl=1.24-6.27, $p=0.01)$. The area under the ROC curve (AUC) of the ALT level was $0.63(95 \% \mathrm{Cl}=0.58-0.68, p<0.001)$, which showed that the ALT level was positively associated with MetS.

Conclusions: The overall prevalence of MetS was $61.01 \%$ in the highland indigenous population in Northern Taiwan, which suggests an unignorable health problem that should actively be addressed. Furthermore, these findings indicated that higher serum ALT levels $(>36 \mathrm{U} / \mathrm{L})$ were associated with an increased risk of MetS.

\section{Background}

Metabolic syndrome (MetS), a serious global health concern, is a constellation of different metabolic abnormalities in an individual, including central obesity, hyperglycemia, hypertension, elevated triglyceride levels, and low high-density lipoprotein cholesterol levels [1]. These abnormalities result in an increased risk of cardiovascular events, type II diabetes and chronic kidney disease [2, 3]. Therefore, the identification of risk factors associated with MetS is vital.

According to the Taiwan national survey, the Nutrition and Health Survey in Taiwan (NAHSIT), the prevalence of MetS increased from 13.6\% (1993-1996) to 30\% (2013-2016). Taking the regional and ethnic diversity in Taiwan into consideration, the NAHSIT 2005-2008 investigated the regional differences 
and showed that the indigenous area had the highest prevalence $(52.1 \%)$ compared to the prevalence in the densely populated area, the offshore island and the Hakka area. Additionally, up to $71.6 \%$ of indigenous peoples were overweight or obese [4, 5]. Furthermore, two cross-sectional studies demonstrated a high prevalence of MetS among indigenous populations in Taiwan between 2010 and $2011[6,7]$. Nevertheless, there are still limited studies on MetS among indigenous peoples in Taiwan. Thus, we intend to assess MetS status in an indigenous tribe, the Atayal tribe, which is widely distributed in the northern part of the Central Mountain Range of Taiwan.

Alanine transaminase (ALT) is an enzyme that mainly exists in hepatocytes, and when the liver is injured due to conditions such as viral hepatitis, ALT will be released, resulting in elevated serum ALT levels [8]. A large community study in Taiwan from 2003 to 2004 illustrated that the prevalence of elevated ALT in an adult population was $11.4 \%$, and non-alcoholic fatty liver disease (NAFLD) seemed to be the most common cause of elevated ALT [9]. Moreover, there were 16.5\% adults with abnormal ALT levels in an Atayal indigenous community [10]. Previous cross-sectional studies have reported a positive association between serum ALT level and MetS [11, 12]. A systemic review and meta-analysis and a large cohort study both showed that the increase in serum ALT levels increased the risk of MetS [13, 14]. Therefore, our study aimed to determine the prevalence of MetS with abnormal serum ALT levels among the northern Taiwanese indigenous population.

\section{Methods}

\section{Study design and study population}

This is an observational, population-based, cross-sectional study. Before this study, the minimum sample size for this study was calculated at the initial stage of the study. After previewing a relative smaller population, considering $80 \%$ power, $95 \%$ confidence level, and 0.59 as the metabolic syndrome prevalence rate among indigenous population, we calculated that 276 participants were required to detect at least 2 odds ratios. We collected data from three remote villages in an indigenous community in Northern Taiwan from 2010 through 2015. Subjects were residents who had lived in the community for more than 6 months, aged over 18 and were able to walk to the health station. Every subject completed a questionnaire containing questions regarding basic personal data and medical conditions, including race, age, sex, occupation, and history of hypertension, diabetes and hyperlipidemia. The questionnaires were completed after detailed explanations were provided by the trained interviewers in in-person interviews. Additionally, urine and blood samples were collected. Anthropometric measurements were performed by trained research assistants or nurses under the supervision of a medical doctor. After the exclusion of subjects who were pregnancy or who had incomplete, missing or repeated data, 454 participants were eligible for the analysis. The flow chart diagram (Figure 1) shows a gradual selection of individuals who comprised the subjects for final analysis. The study was approved by the Chang Gung Medical Foundation Institutional Review Board (101-4156A3), and written informed consent was provided by all the subjects before enrollment. 


\section{Definition of metabolic syndrome and abnormal ALT level}

MetS was defined by the revised NCEP/ATPIII criteria from Taiwan Health Promotion Administration [15] [3]. In detail, a diagnosis of MetS requires the presence of three or more of the following factors: 1) waist circumference (WC) $\geq 90 \mathrm{~cm}$ in men or $\geq 80 \mathrm{~cm}$ in women, 2) systolic blood pressure (SBP) $\geq 130 \mathrm{mmHg}$ or diastolic blood pressure (DBP) $\geq 85 \mathrm{mmHg}$ or current use of antihypertensive drugs 3 ) serum HDL-C $<40 \mathrm{mg} / \mathrm{dl}$ in men or $<50 \mathrm{mg} / \mathrm{dl}$ in women, 4) serum triglycerides $\geq 150 \mathrm{mg} / \mathrm{dl}$ or triglycerides-lowering drugs 5) fasting plasma glucose $\geq 100 \mathrm{mg} / \mathrm{dl}$ or current use of anti-hyperglycemic drugs. An abnormal ALT level was defined as a level $>36 \mathrm{U} / \mathrm{L}$ according to the laboratory method used in Chang Gung Memorial Hospital.

\section{Definition of hypertension, diabetes mellitus and hyperlipidemia}

Hypertension was defined by a SBP $\geq 140 \mathrm{mmHg}$ or DBP $\geq 90 \mathrm{mmHg}$, or use of antihypertensive drugs. Diabetes mellitus was defined as a fasting plasma glucose $\geq 126 \mathrm{mg} / \mathrm{dL}$, or glycated hemoglobin $(\mathrm{HbA1c}) \geq 6.5$, or the use of oral hypoglycemic agents or insulin therapy. Hyperlipidemia was defined as $\mathrm{LDL}-\mathrm{C} \geq 130 \mathrm{mg} / \mathrm{dL}$, or triglycerides (TGs) $\geq 150 \mathrm{mg} / \mathrm{dL}$, or total cholesterol $(\mathrm{TC}) \geq 200 \mathrm{mg} / \mathrm{dL}$, or use of lipid-lowering medications.

\section{Anthropometric and laboratory measurements}

Each subject's blood pressure (BP) was measured on the upper arm while they were in a seated position after at least 5 minutes of rest with a standardized electronic sphygmomanometer. WC was measured at the level midway between the iliac crests and the lowest rib margin with the subjects in a standing position. Height was determined by a height-measuring machine while subjects were barefoot and standing in an erect position with their arms by their side and their feet together. Weight measurements were performed with subjects standing at the center of the weighing scale in light clothing without shoes or socks. Body mass index (BMI) was defined as the weight in kilograms divided by the square of the height in meters $\left(\mathrm{kg} / \mathrm{m}^{2}\right)$. Then, we classified the BMI values into 3 main categories according to the definition published by Taiwan Health Promotion Administration: 1) underweight (BMK 18.5$), 2)$ normal weight $(18.5<=\mathrm{BMl}<24)$, and 3) overweight or obesity $(\mathrm{BMI} \geq 24)[16]$.

Blood samples were obtained from the antecubital vein after a 12-h overnight fast. All blood analyses were carried out at the clinical laboratory department of the Linkuo Chang Gung Memorial Hospital, which is certified by the College of American Pathologists. Biochemical markers were analyzed on a Hitachi 7600-210 autoanalyzer (Hitachi, Tokyo, Japan); the biochemical markers included serum TC, HDL-C, TGs, fasting plasma glucose (FPG), ALT, high-sensitivity C-reactive protein (HS-CRP), HbA1c, and uric acid. In detail, the ALT levels were measured by enzymatic method with a matched instrument application (Hitachi, Tokyo, Japan) in the Linkuo Chang Gung Memorial Hospital.

\section{Statistical analysis}


Data are presented as the mean and standard deviation for continuous variables or numbers and percentages for categorical variables. For variables with non-normal distributions, the data are logtransformed for analysis and shown as median (interquartile range). In univariate analysis, independent sample t-tests and chi-square tests were used to compare MetS and non-MetS subjects. The Chi-square test was also performed to determine the differences in two categorical variables and the prevalence of MetS in different serum ALT level groups. Correlations between different cardio-metabolic risk factors and serum ALT levels were assessed with Pearson's correlation coefficient. The odds ratios (ORs) and their 95\% confidence intervals (Cls) were determined for the association between cardiometabolic risk factors and MetS with adjustment for potential confounders, such as age, sex, alcohol drinking and uric acid level. The receiver operating characteristic (ROC) curve was produced to acquire the values of the area under the curve (AUC) with $95 \% \mathrm{Cls}$ and sensitivity and specificity values for the serum ALT level as a predictor of MetS. The analyses mentioned above were performed with SPSS Statistics version 22 (IBM, SPSS Armonk, NY, IBM Corp). A p value of $<5 \%$ was considered to indicate a statistically significant result.

\section{Results}

The baseline characteristics of the study population according to MetS diagnosis are presented in Table 1. A total of 454 participants were enrolled in the analysis, including $215(47.36 \%)$ men and $239(52.64 \%)$ women. There were 277 people with MetS and 177 people without. The prevalence of MetS was $61.01 \%$. The average age was 49.50 years old. People with MetS had a significantly higher ALT level (24.00 (1736) U/L vs. 19.00 (15-26) U/L, $p<0.001$ ) than those without MetS (Table 1). Also, the prevalence of antihypertensive, antilipidemic and antidiabetic medication were 50\% (86/172=50\%), 23.48\% $(85 / 362=23.48 \%)$, and $44.58 \%(37 / 83=44.58 \%)$, respectively.

Furthermore, people with MetS had significantly higher levels of SBP, DBP, WC, BMI, FPG, serum Hb-A1c, TC, HS-CRP, TGs, and uric acid than those without MetS (Table 1). People with MetS were also older, more likely to be male and had a higher prevalence of hypertension, diabetes, and hyperlipidemia but lower serum HDL-C levels. However, there were no statistically significant differences in the percentages of alcohol drinkers, smokers and serum total bilirubin levels between the two groups.

The comparisons of the prevalence of MetS in different ALT levels ( $>36 \mathrm{U} / \mathrm{L}$ and $\leq 36 \mathrm{U} / \mathrm{L}$ ) groups and the total study group are shown in Figure 2, left panel. The chi-square comparison showed that participants with ALT levels $>36 \mathrm{U} / \mathrm{L}$ had a tendency towards a higher prevalence of MetS $(76.7 \%$ vs. $57.3 \%, p=0.001)$ compared with the prevalence of those with ALT levels $\leq 36 \mathrm{U} / \mathrm{L}$. The bar chart illustrates that the ALT levels $>36 \mathrm{U} / \mathrm{L}$ group had the highest MetS prevalence among the groups (Figure 2, left panel). The chisquare comparison also showed that female participants with ALT levels $>36 \mathrm{U} / \mathrm{L}$ had a tendency towards a higher prevalence of MetS $(88.9 \%$ vs. $61.1 \%, p=0.001)$ compared with the prevalence of those with ALT levels $\leq 36 \mathrm{U} / \mathrm{L}$ (Figure 2, right panel). 
The correlations between serum ALT level and cardiometabolic risk factors are displayed in Table 2. The age-adjusted Pearson's coefficients of BMI, SBP, DBP, WC, FPG and HS-CRP were $0.21(p<0.001), 0.14$ $(p=0.01), 0.18(p<0.001), 0.26(p<0.001), 0.11(p=0.03)$, and $0.14(p=0.01)$, respectively, which indicated positive linear relationships with serum ALT levels (Table 2). The age-adjusted Pearson's coefficient of HDL-C was -0.12 ( $p=0.02)$, which indicated a weak negative linear relationship with serum ALT levels. The serum $\mathrm{Hb}-1 \mathrm{Ac}, \mathrm{TC}, \mathrm{TG}$ and uric acid levels had no statistically significant correlations with the serum ALT level.

The ORs of cardiometabolic risk factors for MetS are shown in Table 3. In the univariate logistic regression model, the crude ORs of ALT levels $>36 \mathrm{U} / \mathrm{L}$, each additional year of age, sex (men versus women), alcohol drinking (yes versus no) , $B M I \geqq 24 \mathrm{~kg} / \mathrm{m}^{2}$, serum HS-CRP and uric acid levels for MetS were 2.46 (95\% $\mathrm{Cl}=1.43-4.22, \mathrm{p}=0.001), 1.04$ (95\% $\mathrm{Cl}=1.03-1.05, \mathrm{p}<0.001), 1.46$ (95\% $\mathrm{Cl}=1.00-2.13$, $\mathrm{p}=0.05), 1.36(95 \% \mathrm{Cl}=0.77-2.39, \mathrm{p}=0.29),, 7.31$ (95\% $\mathrm{Cl}=4.72-11.32, \mathrm{p}<0.001), 1.04$ (95\% $\mathrm{Cl}=0.99-1.09$, $\mathrm{p}=0.14)$, and $1.25(95 \% \mathrm{Cl}=1.12-1.40, \mathrm{p}<0.001)$, respectively. In the univariate logistic regression model, the adjusted ORs of ALT levels $>36 \mathrm{U} / \mathrm{L}$, each additional year of age, sex (men versus women), alcohol drinking (yes versus no), BMI $\geqq 24 \mathrm{~kg} / \mathrm{m}^{2}$, serum HS-CRP and uric acid levels for MetS were $2.79(95 \%$ $\mathrm{Cl}=1.24-6.27, \mathrm{p}=0.01), 1.06(95 \% \mathrm{Cl}=1.04-1.08, \mathrm{p}<0.001), 2.88(95 \% \mathrm{Cl}=1.57-5.29, \mathrm{p}=0.001), 2.19$ (95\% $\mathrm{Cl}=1.09-4.41, \mathrm{p}=0.03), 9.40(95 \% \mathrm{Cl}=4.90-18.01, \mathrm{p}<0.001), 1.00(95 \% \mathrm{Cl}=0.94-1.05, \mathrm{p}=0.86)$, and 1.22 (95\% $\mathrm{Cl}=1.02-1.45, \mathrm{p}=0.03$ ), respectively (Table 3 ). The adjusted ORs of $\mathrm{BMI}<18.5 \mathrm{~kg} / \mathrm{m}^{2}$ for MetS were not statistically significant.

Finally, the AUC of the serum ALT level was $0.63(95 \% \mathrm{Cl}=0.58-0.68, \mathrm{p}<0.001)$, which showed that the serum ALT level was positively associated with MetS, and the cut-off point was $20.50 \mathrm{U} / \mathrm{L}$ (Table 4, Figure $3)$.

\section{Discussion}

The main finding of the present study is the high prevalence of MetS in a Taiwan indigenous population, and there was an association between serum ALT levels and MetS. Higher serum ALT levels, especially over $36 \mathrm{U} / \mathrm{L}$, were associated with an increased risk of MetS.

The results were consistent with the findings of several previous studies. A hospital-based study showed that more than half of the indigenous adults in southeastern Taiwan had MetS [6], and two communitybased studies revealed that the prevalence of MetS in indigenous populations in northern Taiwan was over $48 \%[7,17]$. In contrast, without regard to regional difference, the data from the Taiwan Health Promotion Administration revealed that the overall prevalence of MetS in Taiwanese adults above the age of 20 was 19.7\% in 2007 [15]. According to a cross-sectional survey, the MetS prevalence in a Taiwan metropolitan area was 33.32\% among adults aged over 40 years in 2007 [18]. Therefore, it seems that the prevalence of MetS is higher in the Atayal tribe than in the metropolitan or overall population in Taiwan. This inference was in line with the results of the 2005-2008 NAHSIT, which revealed that the highest prevalence of MetS was found in the indigenous area (mountains) compared to the prevalence in other 
places in Taiwan [4]. Additionally, this idea was supported by a cross-sectional study illustrating that indigenous groups in Taiwan had a markedly higher prevalence of MetS than the Taiwanese and Hakka groups [19].

The reasons for the above phenomenon could be multifactorial. First, there were some health disparities between indigenous individuals and the general population in Taiwan [20]. For example, the lifetime prevalence of alcoholism according to ICD or DSM in four Taiwanese indigenous groups was $40-60 \%$ [21], and a large prospective cohort study revealed that heavy alcohol consumption is associated with an increased risk of the MetS [22]. In addition, a study suggested that $6 \%$ of inhabitants in Kaohsiung, the second-largest city of Taiwan, were current betel chewers, whereas $42 \%$ of the indigenous individuals aged over 15 years in southern Taiwan were current chewers [23]. Although areca nut chewing is deeply rooted in indigenous culture and symbolizes social belonging in Taiwan [24], chronic areca nut chewing is one of the independent risk factors for MetS and contributes to metabolic derangements via the involvement of tumor necrosis factor- $\alpha$, leptin, and leukocyte count [25].

Second, there is a socioeconomic gap between the indigenous people and the general public in Taiwan. According to the economic status survey from the Council of Indigenous Peoples in Taiwan, the indigenous household income was approximately $61 \%$ of the average household income of Taiwan in 2014 , and only $6.58 \%$ of primary income earners had a university education or above [26]. However, a study suggested that good socioeconomic status could protect against MetS [27], and a study with a large sample size also implied that a higher education level was related to a lower risk of MetS [28]. In other words, low socioeconomic status could negatively impact the health of indigenous people. Third, the indigenous population in our study was located in the mountains without adequate healthcare resources, and the lack of medical accessibility caused them to delay seeking care to improve their health outcomes. In summary, differences in health behaviors, low socioeconomic status and limited access to healthcare in remote areas all impacted the health inequality between the Atayal tribe and individuals from metropolitan areas.

In the present study, the second major finding was that baseline serum ALT level and MetS were positively associated with the cut-off point of $20.50 \mathrm{U} / \mathrm{L}$ based on the AUC, and the adjusted OR of ALT levels $>36 \mathrm{U} / \mathrm{L}$ for MetS was 2.79 after correction for age, sex, alcohol drinking, BMI, serum HS-CRP and uric acid levels. These results corroborate the findings from a large-population, community-based study conducted in China, which verified a positive correlation between normal serum ALT levels and the morbidity rate of MetS after age and BMI correction. The optimal ALT boundary value based on the ROC curve was 24.5 for men and 14.5 U/L for women [29]. In short, an elevated ALT level, even at a level still within the reference interval, may reflect early metabolic changes.

On the other hand, our study also implied that an ALT level $>36 \mathrm{U} / \mathrm{L}$ was associated with a tendency towards a higher prevalence of MetS compared to the prevalence associated with ALT levels $\leq 36 \mathrm{U} / \mathrm{L}$. The finding was similar to the results of prior studies. A systematic review and meta-analysis revealed that the baseline circulating ALT level is associated with the risk of MetS and exhibits a linear dose- 
response relationship [14], which was identical to the results of a cross-sectional study including over 15000 adults and a longitudinal study with 7 years of follow-up from China [12] [13]. Taken together, these research studies have indicated that people with higher ALT levels have a higher risk of MetS.

In addition, a Korean study also confirmed that serum ALT levels were positively associated with MetS and its components (FPG, TGs, BP, and WC) [11], and we also found weak positive linear relationships between serum ALT levels and cardiometabolic risk factors (BMI, SBP, DBP, WC, FPG, HS-CRP) in our study. Although the present study only included adults aged over 18 , a nationwide study conducted in Iran indicated that MetS and some cardiometabolic risk factors were significantly associated with ALT levels in children and adolescents aged 7-18 years [30].

Although the mechanisms underlying the association between serum ALT levels and MetS are not entirely understood, a study from the Netherlands shed light on a possible mechanism. Insulin resistance acts as a major mediator of the association between the MetS and ALT level, while inflammatory adipokines, endothelial dysfunction, and nonesterified fatty acids also play minor roles but to a lesser extent [31]. ALT is a catalyzer that is involved in the transfer of the amino group of alanine to a-ketoglutarate [32], and a study from Argentina proposed that abnormal ALT levels are related to a dysregulation of normal amino acid metabolism in the liver, and aberrant liver metabolism could lead to MetS and insulin resistance [33]. Further studies are required to better clarify the pathophysiology.

\section{Conclusions}

In the present study, the overall prevalence of MetS was high in an indigenous population in Northern Taiwan, and higher serum ALT levels, especially those over $36 \mathrm{U} / \mathrm{L}$, were associated with an increased risk of MetS. Further studies need to be performed in regard to this serious health problem in indigenous communities of Taiwan.

\section{Strengths and limitations}

A key strength of this study is that to the best of our knowledge, there were few community-based studies demonstrating the association between serum ALT levels and MetS, especially targeting the Northern Taiwan indigenous population. Furthermore, it demonstrated high prevalence of MetS and the positive association between baseline serum ALT levels and MetS in the Taiwan Atayal tribe. Accordingly, the result of study enhanced the knowledge of the Northern Taiwan indigenous population in public health scopes.

There were also four limitations in this study. First, the cross-sectional design inherently limited in the ability to effectively determine the causal relationship between MetS and serum ALT levels. Second, the serum ALT is a sensitive marker for liver dysfunction and affected by heavy alcohol consumption [34] and some medications [35], but some of the study population had several risk factors, including 
hypertension, and dyslipidemia. Hence, we could not eliminate the possible effect of underlying diseases and medications used for these diseases on the present findings. There was also no clear personal history for viral hepatitis and NAFLD. Third, there were more female subjects than male subjects. The participants in the study were from three remote villages of Taoyuan City and had lived in these villages for over 6 months. The shift from rural low-wage labor to metropolitan higher-paying jobs reduced the available number of indigenous men in the mountain region. Fourth, there are selection bias and limited external validity in the study because the data were originated from 3 villages. Our study population just represented highland indigenous population in northern part of Taiwan. Therefore, more comprehensive and meticulous consideration should be used in future studies. Further prospective population-based studies are needed to investigate the mechanisms in order to improve the above problems.

\section{Abbreviations}

MetS: metabolic syndrome; NCEP: National Cholesterol Education Program Expert Panel; ATP III: Adult Treatment Panel III; NAFLD: non-alcoholic fatty liver disease; SBP: systolic blood pressure; DBP: diastolic blood pressure; WC: waist circumference; ALT: alanine aminotransferase; FPG: fasting plasma glucose; HbA1c: glycated hemoglobin; HDL-C: high-density lipoprotein cholesterol; HS-CRP: high-sensitivity Creactive protein; TC: total cholesterol; TG: triglyceride; BMI: body mass index; HTN: hypertension; DM: diabetes mellitus.

\section{Declarations}

\section{Acknowledgements}

Not applicable.

\section{Funding}

We appreciate Chang Gung Memorial Hospital (grants CORPG3C0021, CORPG3C0022, CORPG3C0023, CMRPG3F0761, CMRPG3F0762, CMRPG3F0763) for supporting this study.

\section{Availability of data and materials}

The datasets used and/or analyzed during the current study are available from the corresponding authors upon reasonable request.

\section{Authors' contributions}


Yi-Fang Chen was involved in writing of the manuscript. Yen-An Lin, Wei-Chung Yeh, Yu-Chung Tsao, WenCheng Li and I-Ju Chen provided opinions about the study designs and help collect data. Jau-Yuan Chen contributed conceived, designed and performed the experiments, collected and analyzed the data, revising it critically for important intellectual content and final approval of the version to be submitted.

\section{Ethics approval and consent to participate}

The study was approved by Chang-Gung Medical Foundation Institutional Review Board (99-0231B, 1014156A3), and written informed consent was provided by all the participants before enrollment.

\section{Consent for publication}

Not applicable.

\section{Competing interests}

The authors declare that they have no competing interests.

\section{References}

1. Alberti KG, Eckel RH, Grundy SM, Zimmet PZ, Cleeman JI, Donato KA, Fruchart JC, James WP, Loria CM, Smith SC, Jr.: Harmonizing the metabolic syndrome: a joint interim statement of the International Diabetes Federation Task Force on Epidemiology and Prevention; National Heart, Lung, and Blood Institute; American Heart Association; World Heart Federation; International Atherosclerosis Society; and International Association for the Study of Obesity. Circulation 2009, 120:1640-1645.

2. Gami AS, Witt BJ, Howard DE, Erwin PJ, Gami LA, Somers VK, Montori VM: Metabolic syndrome and risk of incident cardiovascular events and death: a systematic review and meta-analysis of longitudinal studies. J Am Coll Cardiol 2007, 49:403-414.

3. Ding C, Yang Z, Wang S, Sun F, Zhan S: The associations of metabolic syndrome with incident hypertension, type 2 diabetes mellitus and chronic kidney disease: a cohort study. Endocrine 2018, 60:282-291.

4. Yeh CJ, Chang HY, Pan WH: Time trend of obesity, the metabolic syndrome and related dietary pattern in Taiwan: from NAHSIT 1993-1996 to NAHSIT 2005-2008. Asia Pac J Clin Nutr 2011, 20:292-300. 
5. The report of the Nutrition and Health Survey in Taiwan (NASHIT) from 2013 to 2016. https://www.hpa.gov.tw/Pages/ashx/File.ashx?FilePath= /File/Attach/10443/File_11960.pdf. Accessed 22 Sep 2019.

6. Hsiao Y-C, Wang K, Bair M-J: Prevalence of obesity and metabolic syndrome in Aboriginals in Southeastern Taiwan-a Hospital-based study. J Intern Med Taiwan 2011, 22:48-56.

7. Ho C-I, Tsao Y-C, Chen J-Y, Chang K-C, Tsai Y-W, Lin J-s, Chang S-S: Gamma-glutamyl transpeptidase and the metabolic syndrome in a Taiwanese aboriginal population. International Journal of Diabetes in Developing Countries 2013, 33:147-154.

8. Liu Z, Que S, Xu J, Peng T: Alanine aminotransferase-old biomarker and new concept: a review. International journal of medical sciences 2014, 11:925.

9. Chen $\mathrm{CH}$, Huang MH, Yang JC, Nien CK, Yang CC, Yeh YH, Yueh SK: Prevalence and etiology of elevated serum alanine aminotransferase level in an adult population in Taiwan. Journal of gastroenterology and hepatology 2007, 22:1482-1489.

10. Lin C-F, Shiau T-J, Ko Y-C, Chen P-H, Wang J-D: Prevalence and determinants of biochemical dysfunction of the liver in Atayal Aboriginal community of Taiwan: Is betel nut chewing a risk factor? BMC gastroenterology 2008, 8:13.

11. Lee S-H, Cho D-Y, Joo N-S, Kim K-M, Kim K-N: The relationship of alanine aminotransferase to metabolic syndrome in a Korean population. The Turkish Journal of Gastroenterology 2018, $29: 52$.

12. Wu P, Chen Q, Chen L, Zhang P, Xiao J, Chen X, Liu M, Wang S: Dose-Response relationship between alanine aminotransferase levels within the reference interval and metabolic syndrome in chinese adults. Yonsei medical journal 2017, 58:158-164.

13. Sun H, Liu Q, Wang X, Li M, Fan Y, Song G, Liu Y: The longitudinal increments of serum alanine aminotransferase increased the incidence risk of metabolic syndrome: A large cohort population in China. Clinica Chimica Acta 2019, 488:242-247.

14. Kunutsor SK, Seddoh D: Alanine aminotransferase and risk of the metabolic syndrome: a linear doseresponse relationship. PloS one 2014, 9:e96068.

15. The criteria of adult metabolic syndrome 2007. https://www.hpa.gov.tw/Pages/Detail.aspx? nodeid=639\&pid=1219. Accessed 22 Sep 2019.

16. BMI Calculation. https://health99.hpa.gov.tw/OnlinkHealth/Onlink_BMI.aspx. Accessed 22 Sep 2019.

17. Yeh W-C, Chang S-S: Relationship between manual labor and metabolic syndrome in aboriginal community. Chinese Journal of Occupational Medicine 2016, 23:101-110.

18. Lin C-C, Liu C-S, Lai M-M, Li C-I, Chen C-C, Chang P-C, Lin W-Y, Lee Y-D, Lin T, Li T-C: Metabolic syndrome in a Taiwanese metropolitan adult population. BMC Public Health 2007, 7:239.

19. Huang H-P, Hsu H-Y, Chung T-C, Sun C-A, Chu C-M, Yang T: An Investigation of Metabolic Syndrome Indicators among Different Ethnic groups-a Case Study from a Health Screening in Pingtung Area. Taiwan Journal of Public Health 2008, 27:250-258. 
20. Juan S-C, Awerbuch-Friedlander T, Levins R: Ethnic density and mortality: aboriginal population health in Taiwan. Public Health Reviews 2016, 37:11.

21. Cheng AT, Chen WJ: Alcoholism among four aboriginal groups in Taiwan: high prevalences and their implications. Alcoholism: Clinical and Experimental Research 1995, 19:81-91.

22. Baik I, Shin C: Prospective study of alcohol consumption and metabolic syndrome. The American journal of clinical nutrition 2008, 87:1455-1463.

23. Ko YC, Chiang TA, Chang SJ, Hsieh SF: Prevalence of betel quid chewing habit in Taiwan and related sociodemographic factors. Journal of oral pathology \& medicine 1992, 21:261-264.

24. Ma W-F, Li C-I, Gritz ER, Tamí-Maury I, Lam C, Lin C-C: A symbol of connectedness between the self and the tribal home: Betel quid in the lives of indigenous Taiwanese. Hu Li Za Zhi 2017, 64:65.

25. Chung F-M, Chang D-M, Chen M-P, Tsai JC-R, Yang Y-H, Shieh T-Y, Shin S-J, Chen TH-H, Tai T-Y, Lee Y$\mathrm{J}$ : Areca Nut Chewing Is Associated With Metabolic Syndrome: Role of tumor necrosis factor-a, leptin, and white blood cell count in betel nut chewing-related metabolic derangements. Diabetes Care 2006, 29:1714-1714.

26. Economic Status Survey of Indigenous Peoples in Taiwan, 2014. https://srda.sinica.edu.tw/srda_freedownload.php?recid=703\&fileid=204. Accessed 22 Sep 2019.

27. Liao C-M, Lin C-M: Life course effects of socioeconomic and lifestyle factors on metabolic syndrome and 10-year risk of cardiovascular disease: A longitudinal study in taiwan adults. International journal of environmental research and public health 2018, 15:2178.

28. Wu HF, Tam T, Jin L, Lao XQ, Chung RY-N, Su XF, Zee B: Age, gender, and socioeconomic gradients in metabolic syndrome: biomarker evidence from a large sample in Taiwan, 2005-2013. Annals of epidemiology 2017, 27:315-322. e312.

29. Shen H, Lu J, Shi T-T, Cheng C, Liu J-Y, Feng J-P, Yang J-K: Correlation between normal range of serum alanine aminotransferase level and metabolic syndrome: A community-based study. Medicine 2018, 97.

30. Kelishadi R, Qorbani M, Heshmat R, Motamed-Gorji N, Motlagh ME, Ziaodini H, Taheri M, Shafiee G, Aminaee T, Ahadi Z: Association of alanine aminotransferase concentration with cardiometabolic risk factors in children and adolescents: the CASPIAN-V cross-sectional study. Sao Paulo Medical Journal 2018, 136:511-519.

31. Jacobs M, Van Greevenbroek MM, Van Der Kallen CJ, Ferreira I, Feskens EJ, Jansen EH, Schalkwijk $\mathrm{CG}$, Stehouwer $\mathrm{C}$ : The association between the metabolic syndrome and alanine amino transferase is mediated by insulin resistance via related metabolic intermediates (the Cohort on Diabetes and Atherosclerosis Maastricht [CODAM] study). Metabolism 2011, 60:969-975.

32. Biochemistry. https://www.ncbi.nlm.nih.gov/books/NBK22475/. Accessed 22 Sep 2019.

33. Sookoian S, Pirola CJ: Alanine and aspartate aminotransferase and glutamine-cycling pathway: their roles in pathogenesis of metabolic syndrome. World journal of gastroenterology: WJG 2012, 18:3775. 
34. Alatalo P, Koivisto H, Puukka K, Hietala J, Anttila P, Bloigu R, Niemelä O: Biomarkers of liver status in heavy drinkers, moderate drinkers and abstainers. Alcohol \& Alcoholism 2008, 44:199-203.

35. Björnsson E: drug-induced liver injury in clinical practice. Alimentary pharmacology \& therapeutics 2010, 32:3-13.

\section{Tables}

Table 1 Study population characteristics according to the presence of MetS.

\begin{tabular}{|c|c|c|c|c|}
\hline \multirow[b]{3}{*}{ Variables } & \multirow[t]{2}{*}{ Total } & \multicolumn{3}{|c|}{ Metabolic syndrome } \\
\hline & & No & Yes & \\
\hline & $(n=454)$ & $(n=177)$ & $(n=277)$ & $\mathrm{p}$ value \\
\hline Age (year) & $49.50 \pm 16.01$ & $43.83 \pm 16.97$ & $53.12 \pm 14.26$ & $<0.001$ \\
\hline SBP (mmHg) & $133.03 \pm 21.26$ & $123.45 \pm 18.21$ & $139.15 \pm 20.84$ & $<0.001$ \\
\hline DBP (mmHg) & $83.80 \pm 13.85$ & $78.82 \pm 12.53$ & $86.97 \pm 13.74$ & $<0.001$ \\
\hline $\mathrm{WC}(\mathrm{cm})$ & $88.62 \pm 11.00$ & $81.23 \pm 9.08$ & $93.37 \pm 9.40$ & $<0.001$ \\
\hline $\operatorname{ALT}(\mathrm{U} / \mathrm{L})^{\mathrm{a}}$ & $22.00 \quad(16-32)$ & $19.00 \quad(15-26)$ & $24.00 \quad(17-36)$ & $<0.001$ \\
\hline FPG $(\mathrm{mg} / \mathrm{dL})^{\mathrm{a}}$ & $\begin{array}{ll}93.00 & (86- \\
& 104.25)\end{array}$ & $(83-92)$ & $\begin{array}{l}(90- \\
117)\end{array}$ & $<0.001$ \\
\hline $\mathrm{Hb}-\mathrm{A} 1 \mathrm{c}(\%)^{\mathrm{a}}$ & $(5.6-6.2)$ & $\begin{array}{l}(5.5- \\
5.9)\end{array}$ & 6.00 & $<0.001$ \\
\hline HDL-C (mg/dL) & $50.47 \pm 13.05$ & $56.40 \pm 11.79$ & $46.68 \pm 12.41$ & $<0.001$ \\
\hline HS-CRP $(\mathrm{mg} / \mathrm{L})^{\mathrm{a}}$ & $\begin{array}{ll}1.48 & (0.72- \\
& 2.94)\end{array}$ & $\begin{array}{ll}0.88 & (0.4- \\
& 2.2)\end{array}$ & $\begin{array}{ll}1.90 & (0.96- \\
3.52)\end{array}$ & $<0.001$ \\
\hline $\mathrm{TC}(\mathrm{mg} / \mathrm{dL})$ & $194.28 \pm 39.79$ & $184.14 \pm 33.21$ & $200.75 \pm 42.27$ & $<0.001$ \\
\hline $\begin{array}{l}\text { Total Bilirubin } \\
(\mathrm{mg} / \mathrm{dL})^{\mathrm{a}}\end{array}$ & $\begin{array}{ll}0.50 & (0.40- \\
& 0.70)\end{array}$ & $\begin{array}{ll}0.50 & (0.4- \\
& 0.7)\end{array}$ & $\begin{array}{ll}0.50 & (0.4- \\
& 0.7)\end{array}$ & 0.24 \\
\hline $\mathrm{TG}(\mathrm{mg} / \mathrm{dL})^{\mathrm{a}}$ & $114.00 \quad(80-183)$ & (62.0- & $\begin{array}{l}(103.5- \\
2150)\end{array}$ & $<0.001$ \\
\hline $\begin{array}{l}\text { Uric Acid } \\
\text { (mg/dL) }\end{array}$ & $6.36 \pm 1.88$ & $5.91 \pm 1.78$ & $6.65 \pm 1.88$ & $<0.001$ \\
\hline Men, $\mathrm{n}(\%)$ & $47.36 \%$ & $53.11 \%$ & $43.68 \%$ & 0.0498 \\
\hline ALT & & & & 0.001 \\
\hline$\leqq 36 \mathrm{U} / \mathrm{L}$ & $81.06 \%$ & $88.70 \%$ & $76.17 \%$ & \\
\hline$>36 \mathrm{U} / \mathrm{L}$ & $18.94 \%$ & $11.30 \%$ & $23.83 \%$ & \\
\hline BMI & & & & $<0.001$ \\
\hline$<18.5$ & $2.21 \%$ & $4.55 \%$ & $0.72 \%$ & \\
\hline $18.5-24$ & $33.55 \%$ & $58.52 \%$ & $17.69 \%$ & \\
\hline$\geqq 24$ & $64.24 \%$ & $36.93 \%$ & $81.59 \%$ & \\
\hline HTN, n(\%) & $38.05 \%$ & $19.89 \%$ & $49.64 \%$ & $<0.001$ \\
\hline $\mathrm{DM}, \mathrm{n}(\%)$ & $20.70 \%$ & $2.82 \%$ & $32.13 \%$ & $<0.001$ \\
\hline $\begin{array}{l}\text { Hyperlipidemia, } \\
\text { n(\%) }\end{array}$ & $79.74 \%$ & $54.24 \%$ & $96.03 \%$ & $<0.001$ \\
\hline Smoking, n(\%) & $13.78 \%$ & $12.28 \%$ & $14.65 \%$ & 0.56 \\
\hline $\begin{array}{l}\text { Alcohol drinking, } \\
\text { n(\%) }\end{array}$ & $22.61 \%$ & $19.30 \%$ & $24.50 \%$ & 0.29 \\
\hline
\end{tabular}


Notes: Clinical characteristics are presented as mean \pm SD for continuous variables and $\mathrm{n}$ (\%) for categorical variables. Variables with non-normal distributions are log-transformed for analysis and shown as median (interquartile range). P-value were derived from independent t-test for continuous variables and chi-square test for categorical variables. ${ }^{a}$ is considered as log-transformed variables.

Abbreviations: SBP, systolic blood pressure; DBP, diastolic blood pressure; WC, waist circumference; ALT, alanine aminotransferase; FPG, fasting plasma glucose; HbA1c, glycated hemoglobin; HDL-C, high-density lipoprotein cholesterol; HS-CRP, high-sensitivity C-reactive protein; TC, total cholesterol; TG, triglyceride; BMI, body mass index; HTN, hypertension; DM, diabetes mellitus.

Table 2 The correlations between ALT and cardiometabolic risk factors.

\begin{tabular}{|c|c|c|c|c|}
\hline \multirow[b]{3}{*}{ Variables } & \multicolumn{4}{|c|}{ ALT U/L $(n=454)$} \\
\hline & \multicolumn{2}{|c|}{ Unadjusted } & \multicolumn{2}{|c|}{ Adjusted for age } \\
\hline & $\overline{\text { Pearson's coe }}$ & $\mathrm{p}$ value & $\overline{\text { Pearson's cot }}$ & p value \\
\hline Age (year) & -0.07 & 0.147 & NA & NA \\
\hline $\operatorname{BMI}\left(\mathrm{kg} / \mathrm{m}^{2}\right)$ & 0.24 & $<0.001$ & 0.21 & $<0.001$ \\
\hline SBP (mmHg) & 0.11 & 0.02 & 0.14 & 0.01 \\
\hline DBP $(\mathrm{mmHg})$ & 0.16 & $<0.001$ & 0.18 & $<0.001$ \\
\hline $\mathrm{WC}(\mathrm{cm})$ & 0.26 & $<0.001$ & 0.26 & $<0.001$ \\
\hline FPG (mg/dL) & 0.09 & 0.04 & 0.11 & 0.03 \\
\hline Hb-A1c (\%) & 0.08 & 0.08 & 0.09 & 0.10 \\
\hline HDL-C (mg/dL) & -0.12 & 0.01 & -0.12 & 0.02 \\
\hline HS-CRP ( mg/L ) & 0.15 & 0.001 & 0.14 & 0.01 \\
\hline $\mathrm{TC}(\mathrm{mg} / \mathrm{dL})$ & 0.02 & 0.60 & 0.01 & 0.82 \\
\hline Total Bilirubin (mg/dL) & 0.19 & $<0.001$ & 0.23 & $<0.001$ \\
\hline TG (mg/dL) & 0.11 & 0.02 & 0.09 & 0.09 \\
\hline Uric Acid (mg/dL) & 0.10 & 0.03 & 0.10 & 0.05 \\
\hline
\end{tabular}

Abbreviations: ALT, alanine aminotransferase; BMI, body mass index; SBP, systolic blood pressure; DBP, diastolic blood pressure; WC, waist circumference; FPG, fasting plasma glucose; HbA1c, glycated hemoglobin; HDL-C, high-density lipoprotein cholesterol; HS-CRP, high-sensitivity C-reactive protein; TC, total cholesterol; TG, triglyceride.

Table 3 Univariate and multivariate logistic regression on the cardiometabolic risk factors related to MetS among study population. 


\begin{tabular}{|c|c|c|c|c|c|c|}
\hline Variables & $\begin{array}{l}\text { Crude Odds } \\
\text { Ratio }\end{array}$ & $(95 \% \mathrm{CI})$ & p value & $\begin{array}{c}\text { Adjusted Odds } \\
\text { Ratio }\end{array}$ & $(95 \% \mathrm{CI})$ & p value \\
\hline $\begin{array}{l}\text { ALT (>36U/L versus } \\
\leqq 36 \mathrm{U} / \mathrm{L})\end{array}$ & 2.46 & $\begin{array}{l}(1.43- \\
4.22)\end{array}$ & 0.001 & 2.79 & $\begin{array}{l}(1.24- \\
6.27)\end{array}$ & 0.01 \\
\hline$\overline{\text { Age }}$ (year) & 1.04 & $\begin{array}{l}(1.03- \\
1.05)\end{array}$ & $<0.001$ & 1.06 & $\begin{array}{l}(1.04- \\
1.08)\end{array}$ & $<0.001$ \\
\hline Sex (men versus women) & 1.46 & $\begin{array}{l}(1.00- \\
2.13)\end{array}$ & 0.05 & 2.88 & $\begin{array}{l}(1.57- \\
5.29)\end{array}$ & 0.001 \\
\hline $\begin{array}{l}\text { Alcohol drinking (yes } \\
\text { versus no) }\end{array}$ & 1.36 & $\begin{array}{l}(0.77- \\
2.39)\end{array}$ & 0.29 & 2.19 & $\begin{array}{l}(1.09- \\
4.41)\end{array}$ & 0.03 \\
\hline \multicolumn{7}{|l|}{ BMI $\left(\mathrm{kg} / \mathrm{m}^{2}\right)$} \\
\hline$<18.5$ & 0.53 & $\begin{array}{l}(0.11- \\
2.57)\end{array}$ & 0.43 & 1.53 & $\begin{array}{l}(0.19- \\
12.32)\end{array}$ & 0.69 \\
\hline $18.5-24$ & 1.00 & & - & 1.00 & - & - \\
\hline$\geqq 24$ & 7.31 & $\begin{array}{l}(4.72- \\
11.32)\end{array}$ & $<0.001$ & 9.40 & $\begin{array}{l}(4.90- \\
18.01)\end{array}$ & $<0.001$ \\
\hline HS-CRP (mg/L) & 1.04 & $\begin{array}{l}(0.99- \\
1.09)\end{array}$ & 0.14 & 1.00 & $\begin{array}{l}(0.94- \\
1.05)\end{array}$ & 0.86 \\
\hline Uric Acid (mg/dL) & 1.25 & $\begin{array}{l}(1.12- \\
1.40)\end{array}$ & $<0.001$ & 1.22 & $\begin{array}{l}(1.02- \\
1.45) \\
\end{array}$ & 0.03 \\
\hline
\end{tabular}

Abbreviations: ALT, alanine aminotransferase; BMI, body mass index; HS-CRP, highsensitivity C-reactive protein.

Table 4 The areas under ROC curve (AUC), sensitivity, specificity by the optimized cut-off points for ALT in predicting metabolic syndrome.

\begin{tabular}{lccccc} 
Variables & AUC(95\% CI) & p value & $\begin{array}{c}\text { Cut-off } \\
\text { point }\end{array}$ & Sensitivity & Specificity \\
\hline ALT & $0.63(0.58-$ & $<0.001$ & 20.500 & 0.643 & 0.559 \\
$(\mathrm{U} / \mathrm{L})$ & $0.68)$ & & & & \\
\hline
\end{tabular}

Abbreviations: ALT, alanine aminotransferase; ROC curve, receiver operating characteristic curve; CI, confidence interval.

Figures 


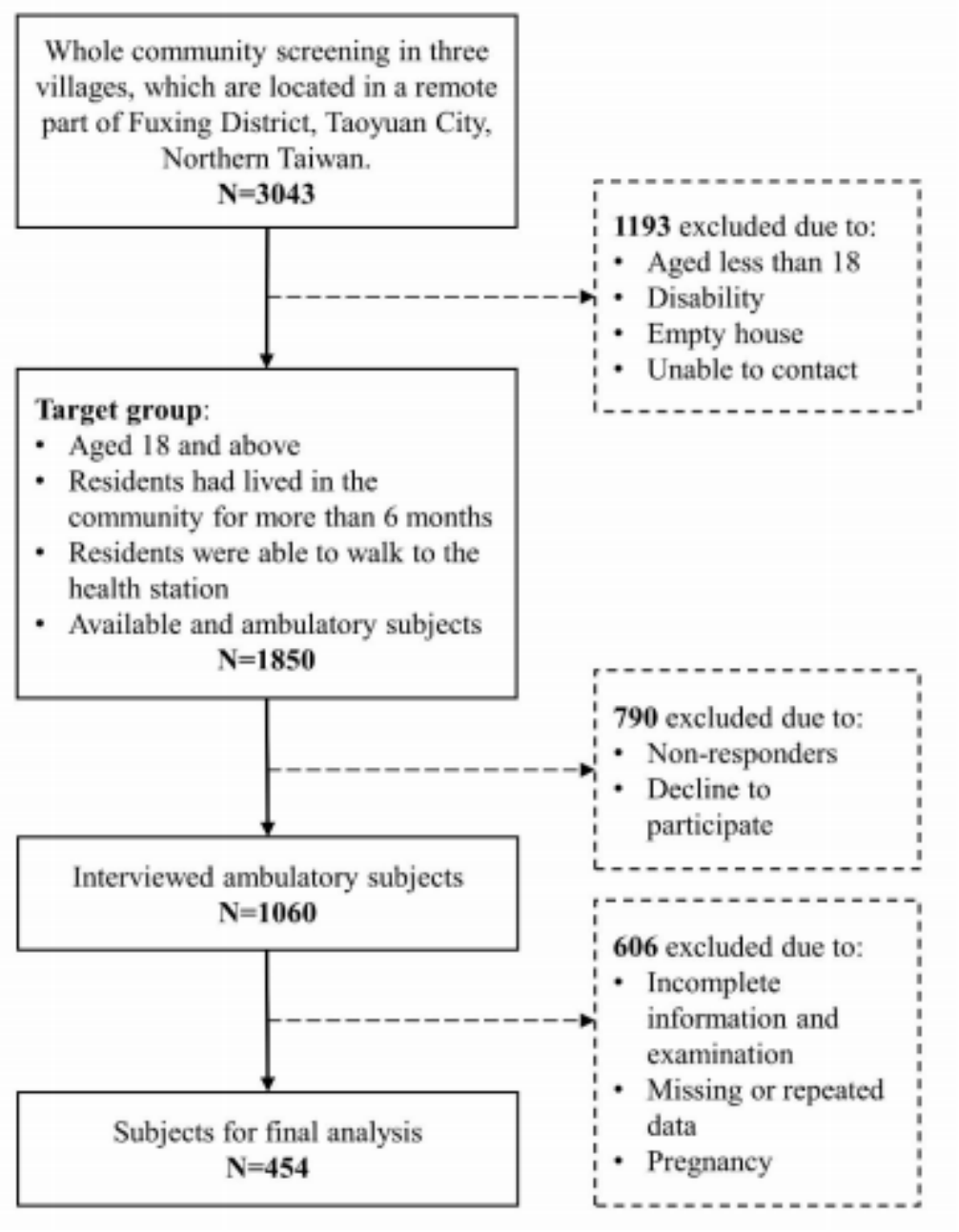

Figure 1

Flow chart of the study subjects.
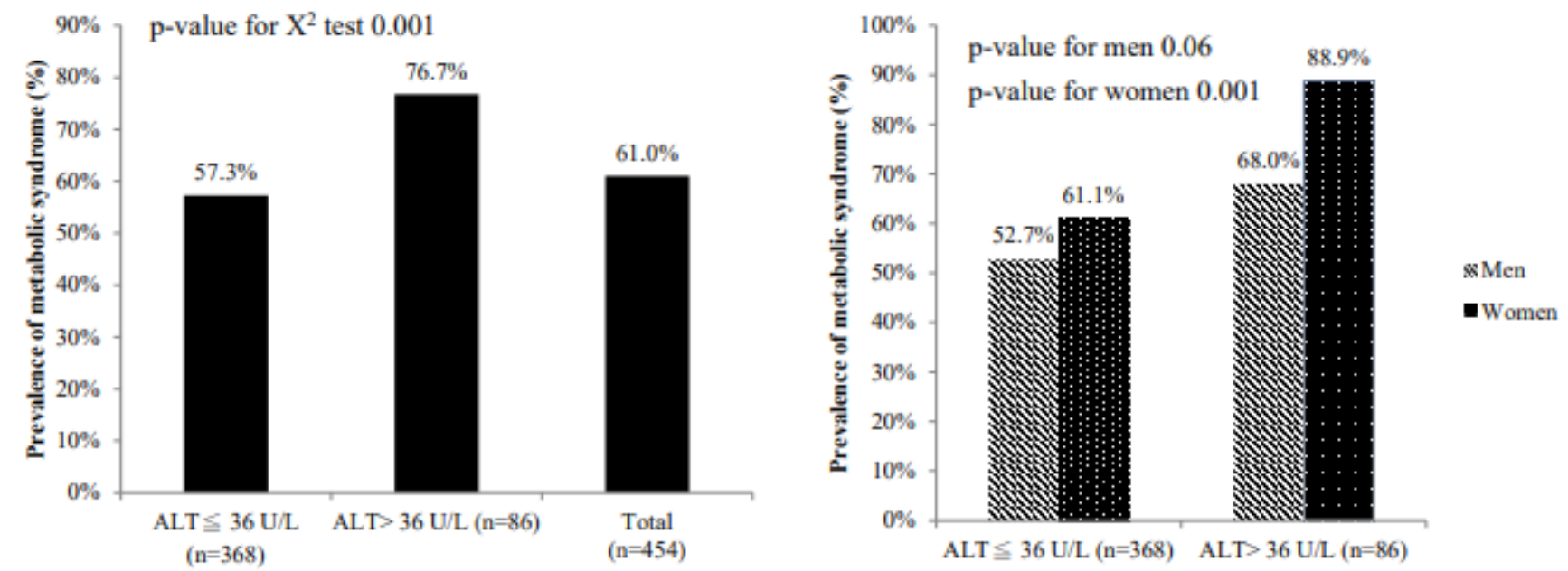

Figure 2 
The comparisons of the prevalence of MetS in different ALT levels groups and the total study group (left panel) and the prevalence of MetS of men and women in different ALT levels groups (right panel).

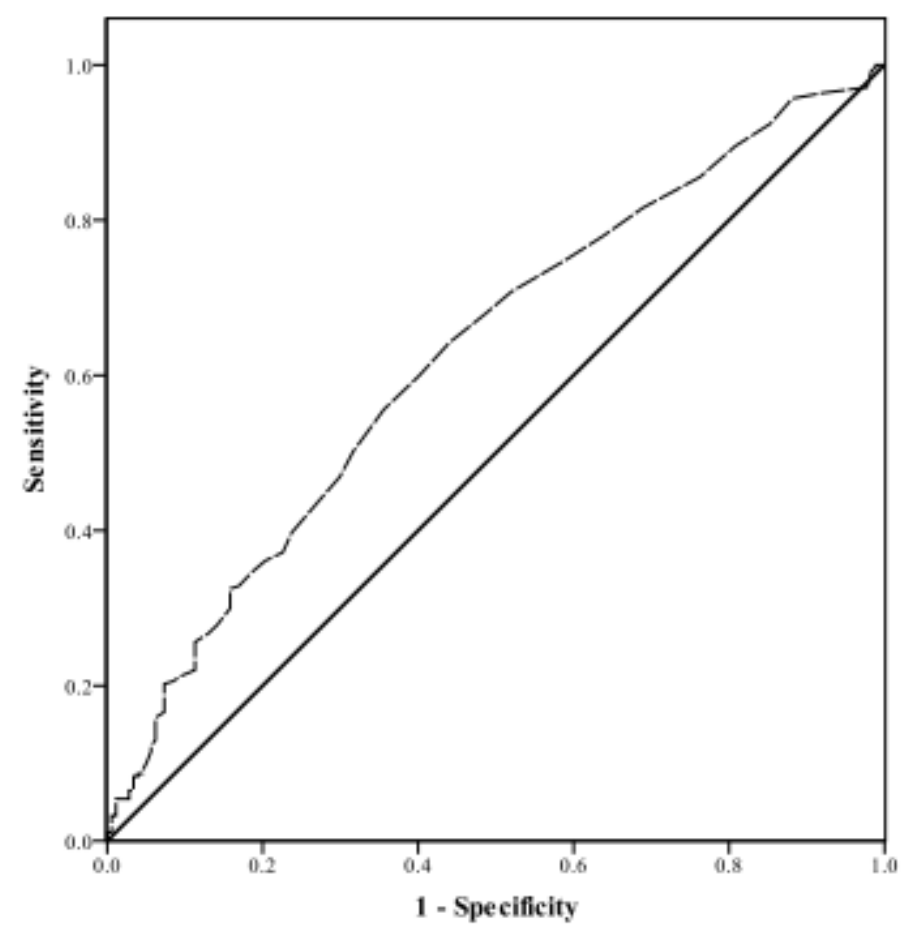

Figure 3

ROC curve and AUC for ALT as a predictor of MetS.

\section{Supplementary Files}

This is a list of supplementary files associated with this preprint. Click to download.

- STROBEchecklistcrosssectional0505.doc 